\title{
Auroville Ekoköyü ve Erdem Bahçeleri
}

\section{Osman ZEYBEK \\ Bursa Uludağ Üniversitesi Ziraat Fakültesi Peyzaj Mimarlığı Bölümü, Bursa, Türkiye}

\section{Öz}

Ekoköy akımı, kentlerin birer ekolojik yıkım merkezi olmasının akabinde, ekolojik dengeyi yeniden sağlamak için en umut verici yollardan biri olarak görülmektedir. Çalışma kapsamında incelenen Auroville ekoköyü, sahip olduğu ekolojik zenginlikleri ve spiritüel boyutu ile oldukça dikkat çekmektedir. Ekoköyde yaşayan insanların ruhsal sağllğı için özel bahçeler bile oluşturulmuştur.

Terapi bahçeleri, insanların fiziksel, psikolojik, sosyal ve spiritüel ihtiyaçlarını karşılamak üzere özel olarak tasarlanan açık ve yeşil alanlardır. Literatürde sağlık bahçeleri ya da iyileştirme bahçeleri şeklinde de geçen bu yapılar daha çok hastane bahçeleri, huzur ve sevgi evleri, sürekli bakım merkezleri gibi yerlerde tesis edilmektedir. Bahçelerin odak noktası öncelikle bitkileri ve dost canlısı vahşi yaşamı bir araya getirmektir.

$\mathrm{Bu}$ araştırmada, 1968 yılında Hindistan'da kurulan Auroville ekoköyünün tarihi, tasarım prensipleri ve merkezindeki Matrimandir tapınak kompleksi incelenmiş̧ir. Derleme niteliğinde hazırlanan çalışma, ekoköyler hakkında Türkçe literatürü zenginleştirmek amacıyla elde edilen kaynaklardan Türkçeye tercüme edilmiştir. Auroville gibi, Ekoköy akımının son derece önemli bir temsilcisi olan girişime dair veriler, Auroville arşiv sorumlusu Gilles Guigan ile e-posta üzerinden haberleşerek ve Auroville'in resmi internet sitesinden derlenmiştir.

Anahtar Kelimeler: Ekoköy akımı, Auroville, terapi bahçeleri, erdem bahçeleri.

\section{Auroville Ecovillage and Virtue Gardens}

\section{Abstract}

Ecovillage movement is seen as one of the most promising ways to restore ecological balance to the world, because the cities have become a center of ecological disaster. Auroville ecovillage, which is examined through this work, draws attention by its ecological values and spiritual dimension. There are special gardens for whom lives in that ecovillage to sustain mental health.

Therapeutic gardens are open and green spaces specially designed to meet the physical, psychological, social, and spiritual needs of people. These structures, which are also referred to as health gardens or rehabilitation gardens in the literature, are mostly established in places such as hospital gardens, peace and love houses, and permanent care centers. The focus of the gardens is to bring plants and friendly wildlife together first.

In this research, the history, design principles, and Matrimandir temple complex in the center of Auroville ecovillage, which was established in India in 1968, were investigated. The study, which is prepared as review research, has been translated into Turkish from the sources obtained in order to enrich the Turkish literature on ecovillages. Data about the Auroville initiative, which is an extremely important representative of the ecovillage movement, was compiled by e-mail with Auroville archive manager Gilles Guigan and from the official website of Auroville..

Keywords: Ecovillage movement, Auroville, therapeutic gardens, virtue gardens. 


\section{Giriş}

Dünyanın bozulan sağlığını iyileştirmeye yönelik gerçekleştirilen en radikal girişimlerden biri olan ekoköy hareketi, ekolojik, ekonomik, sosyal ve spiritüel temellere dayalı bir komün yaşam pratiğidir. Zarar gören ekolojik denge neticesinde kaygı duyan insanların, çevrelerine en az zararı vererek ya da verdiği zararı iyileştirerek yaşamayı deneyimledikleri merkezlerdir. Bilinçli insanların bir araya gelerek, boş bir arazide kurdukları bir yerleşim ya da mevcut bir köyde mekânsal ve sosyal değişiklikler yardımıyla ekolojik ayakizinin ciddi ölçüde düşürüldüğü girişimler olmak üzere iki farklı şekilde gelişim gösterebilirler. Her ne kadar ekolojik kaygılara sahip girişimler olsa da ekoköylerin en önemli boyutu spiritüel boyutudur. Çünkü bu yaşam tarzının temelinde "ertesi gün yaşam yeri terk edilse sanki hiç orada yaşanmamış gibi sıfır etkiyle yaşamayı deneyimleme" gayesi yatmaktadır. Hayat tarzında ciddi değişiklikler gerektiren bu amaç doğrultusunda spiritüel motivasyon en önemli yere sahiptir. Çünkü insanların bu yaşam tarzını sıkıldıklarında terk etmelerini engelleyen en önemli faktör bu hareketin spiritüel boyutunda yatmaktadır.

Dünyanın önde gelen ekoköyleri arasında, hikayesinden tasarım ve yaşam pratiklerine kadar spiritüel derinliği ile öne çıkanı kuşkusuz Auroville ekoköyüdür. Auroville ekoköyü, spiritüel uygulamalara verdiği önemle, insanların kusursuzluğa giden yolda ihtiyaç duyabilecekleri mekanları düşünerek tasarlanmış ve gelişimine de aynı amaçla devam etmektedir. Uzak doğu felsefesindeki insanın sahip olması gereken 12 erdeme odaklanmıştır. Tüm bu erdemler üzerine yapılacak meditasyonlarla mükemmel insan seviyesine ulaşmak hedeflenmiştir. Bu amaç için hazırlanan mekanlar arasında en dikkat çekeni, erdem bahçeleri olmuştur.

Erdem bahçeleri, hikayesi ve amacına bakıldığında zihinsel iyileşme sağlayan bir tür terapi bahçesi niteliği taşımaktadır. Amerikan Bahçe Bitkileri Terapi Derneği (The American Horticultural Therapy Association AHTA) tarafından bir terapi bahçesi türü olarak değerlendirilen restorative gardens (onarıcı bahçeler), "zihinsel istirahat, stres azaltma, duygusal iyileşme ve zihinsel \& fiziksel enerjinin geliştirilmesine elverişli bir ortam sağlamak için doğanın onarıcı gücünü kullanan mekanlar” şeklinde tanımlanmaktadır (AHTA 2012).

Bu çalışmada Auroville ekoköyünün tarihi, tasarım prensipleri, Matrimandir tapınağı ve erdem bahçeleri ile ilgili veriler derlenmiştir. Derleme niteliğinde hazırlanan bu araştırmada temel olarak iki kaynak kullanılmıştır.

1976 yılından bu yana Auroville ekoköyünde yapılan her bir etkinliğin kaydı arşivlenmektedir. Auroville ekoköyü ile ilgili ulaşılan bilgiler, arşiv sorumlusu Gilles Guigan tarafından paylaşılmıştır. Yaklaşık bir yıla yayılan, internet aracılığıyla farklı zamanlarda, e-posta ile soru cevap şeklinde yürütülen bilgi alışverişi, Guigan tarafından paylaşılan dokümanlarla tamamlanmıştır. Bu bilgi alışverişi 11 Ocak 2019 ve 6 Aralık 2019 tarihleri arasında tamamlanmıştır. Kullanılan fotoğraflar Guigan tarafından, Auroville arşivinden gönderilmiştir. Bunun yanı sıra, Auroville ekoköyü ile ilgili verilerin bir kısmı da resmi internet sitesinden derlenmiştir.

Dolayısıyla metin içinde Auroville ekoköyü ile verilen bilgilerin tamamı Guigan'ın paylaştığı dokümanlar ve resmi internet sitesinden derlenen bilgilerden edinilmiştir.

\section{Auroville Ekoköyü}

\subsection{Auroville Ekoköyünün Konumu, Nüfusu ve İklim Özellikleri}

Auroville, Hindistan yarımadasının güney doğusunda, Tamil Nadu eyaleti sınırları içinde, 28 Şubat 1968 tarihinde kurulmuştur (Şekil 1). Dünyanın en başarılı ekoköylerinden biri olarak değerlendirilen yerleşke, aynı zamanda dünyanın en büyük ekoköyü olma özelliğine de sahiptir. Bir kasaba büyüklüğünde olmasına rağmen bir ülkenin kültürel çeşitliliğine sahip olan Auroville'de 190 farklı topluluk, 20 kilometrekarelik (1.620 hektar) bir alanda yaşamaktadır. Bu alanın 2.780 dönümü yeşil kemere ayrılmıştır. Tropikal iklime sahip olan yerleşkede hava sıcaklığı aralık, ocak, şubat ve mart aylarında genellikle $24-30{ }^{\circ} \mathrm{C}$ arasında seyrederken Nisan'da $40{ }^{\circ} \mathrm{C}$ 'ye ulaşabilmektedir. Mayıs ve haziran aylarında ara sıra yağış almaya başlayan bölgede temmuz ayından itibaren havalar soğumaya başlar. Ekim, kasım ve aralık ayları ise muson mevsiminin etkisinde geçer. $\mathrm{Bu}$ dönemde de geceleri en düşük sıcaklık genellikle $5{ }^{\circ} \mathrm{C}$ 'dir. Auroville'in rakımı ise 32 metredir (Gangopadhyay and Chakraborty 2015).

Auroville, 40 'tan fazla mimarın yaşadığı, çok çeşitli ve yenilikçi yapı tekniklerinin geliştirildiği bir yerleşkedir. Yenilenebilir enerji, uygun yapı teknolojisi, tasarım ve inşaat alanında yürütülen örnek çalışmaların tanınmasıyla bir dizi ulusal ve uluslararası ödül almışıır. Aldığı ödüller arasında Hassan Fathi Uluslararası Yoksullar Mimarlık Ödülü, Hindistan'ın Kentsel Gelişim ve Yoksullukla Mücadele Bakanlığı’nın En İyi Yapı Merkezi Ödülü, sürdürülebilir enerji alanında Yeşil Oscar olarak bilinen Ashden Girişimcilik ödülü sayılabilir 
(Auroville Resmi İnternet Sitesi 2019).

Fiziksel gelişim açısından Auroville, 'geleceğin şehri' veya 'dünyanın ihtiyacı olan şehir' modeli olmayı hedeflemektedir. Daha uyumlu bir geleceğe içtenlikle bakan insanların yaşamak isteyeceği güzel şehirlere giden yolda ilk adım olmayı amaçlamaktadır.

Günümüzde de 59 farklı ulustan insanın bir arada yaşadığı, yaklaşık 2.500 kişinin yaşadığı bir yerleşimdir. Bu nüfusun 570'i Hindistanlılardan oluşmaktayken, 272 kişi Fransız, 230 kişi Alman, geri kalanını da dünyanın pek çok ülkesinden insanlar oluşturmaktadır. Hindistan'ın güney bölgesinde bulunan Auroville, multikültürel yapısıyla UNESCO tarafından "geleceğin evrensel şehri" ilan edilmiştir (Jonge 2017). Oldukça geniş bir yelpazeye sahip programları vardır ve sürekli ziyaretçi araştırmacılar, üniversite öğrencileri ve uluslararası gönüllüleri ağırlamaktadır. En popüler eğitimler arasında düşük maliyetli bina teknolojisi, sürdürülebilir yaşam, gıda güvenliği ve organik tarım, mimari uygulamalar ve yerleşke planlama bulunmaktadır. Bunların yanı sıra çevre eğitimi, tohum bankaları oluşturma, tıbbi bitkiler, geleneksel botanik bilimi, deneysel eğitim yöntemleri, felsefe, alternatif tıp ve iyileştirme yöntemleri üzerinde bilhassa durulmaktadır. Auroville'de bulunan ormancılık grubu, arazi restorasyonu üzerinde güzel çalışmalar gerçekleştirmektedir ve geniş bir katılım kitlesine sahip bir eğitim merkezi haline gelmiştir (Mueller, 2012).
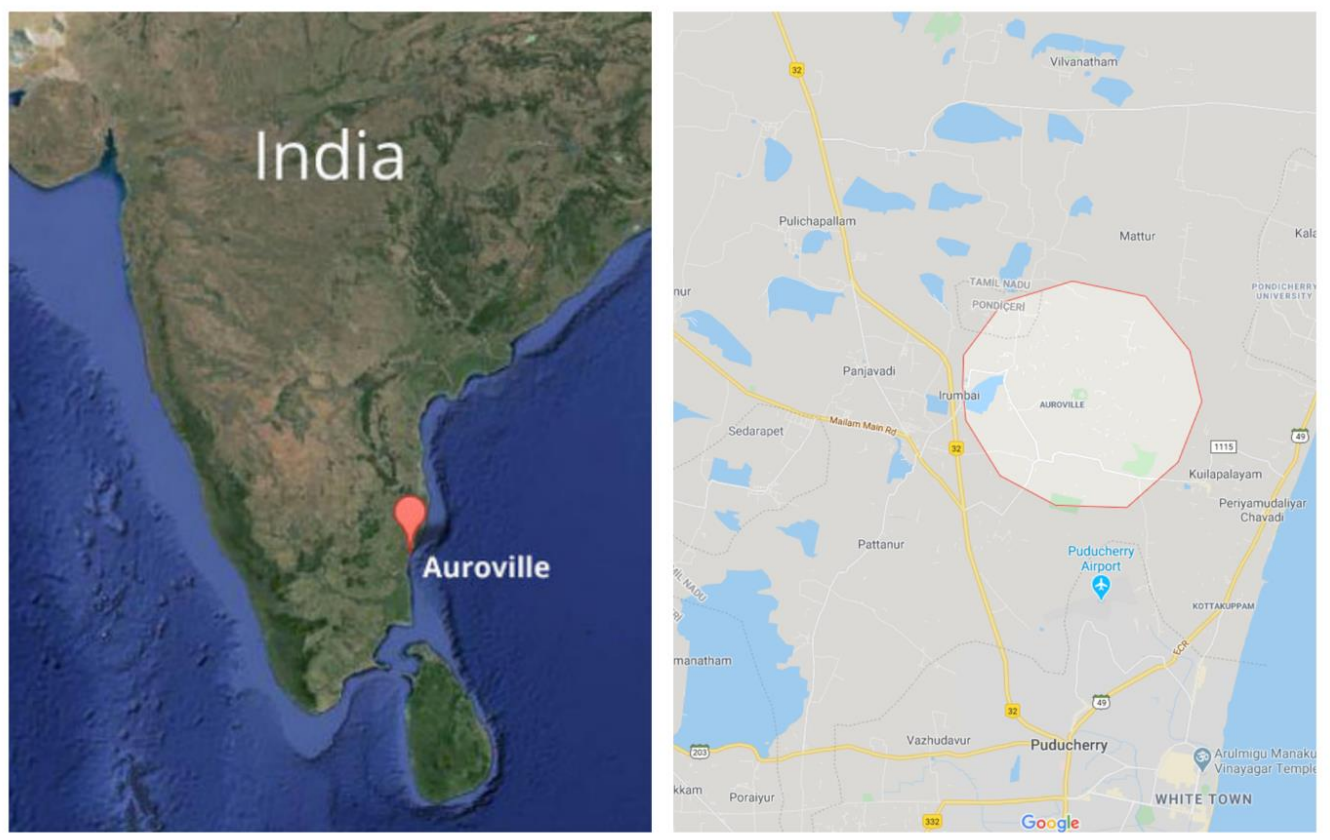

Şekil 1. Auroville ekoköyünün konumu (Google Haritalar 2019).

\subsection{Auroville Ekoköyünün Tarihi}

Auroville'in tarihini özetlerken, Auroville sakinleri tarafından The Mother olarak anılan Mira Alfassa ve Sri Aurobindo'dan bahsetmek gerekmektedir (Şekil 2).

Sri Aurobindo, İngiliz sömürgesi altındaki Hindistan topraklarında, Hindistan'ın bağımsızlığı için mücadele eden bir politikacıdır ve 1905 - 1908 yılları arasında İngiliz hükümeti tarafından "Hindistan'daki en tehlikeli insan" ilan edilmiştir ve politik girişimlerinden dolayı 1908 yılını hapishanede geçirmiştir. Hapisten çıktıktan sonra Fransız sömürgesi altındaki Chandernagore bölgesinde (Güney Hindistan) bir süre yaşamıştır. 1915'te ise Fransa'ya taşınmıştır (Guigan 2019).

Mira Alfassa, Edirneli Türk bir baba ve Misır kökenli bir annenin kızı olarak Fransa'da doğmuştur. Sri Aurobindo ile yolları 1920'de Fransa'da kesişmiştir. Auroville arşivinde Mira Alfassa ve Sri Aurobindo için "ruhani partner" ifadesi kullanılmaktadır. Bu durum, aynı ruhun aynı anda bir kadın ve bir erkek bedeninde dünyaya gönderilmesi şeklinde ifade edilmektedir (Guigan 2019).

Sri Aurobindo, 1926'da büyük bir ruhani farkındalığa erişmiş ve 1950'de vefatına kadar evinden dışarı çıkmamıştır. Bu dönemde Mira Alfassa ile yaptığı meditasyonlar sayesinde, onun da bu farkındalığa erişmesine yardım etmiştir (Guigan 2019). 


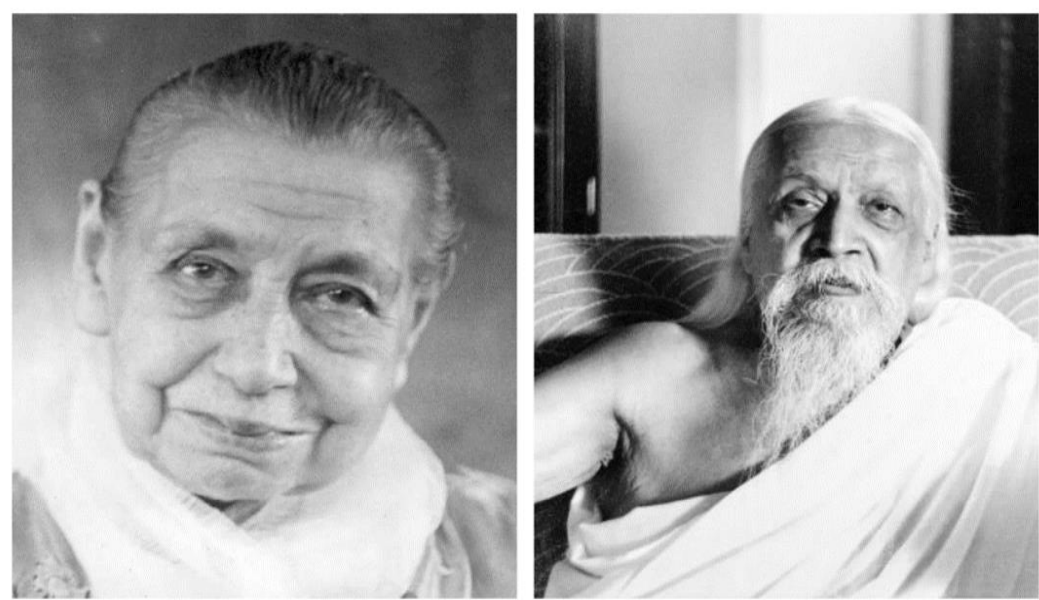

Şekil 2. Mira Alfassa (The Mother) ve Sri Aurobindo (Guigan 2019).

Sri Aurobindo ve Mira Alfassa, dünyaya eşsiz bir miras bırakmak istemiştir. İkisi de dünyanın bozulan sağlığının farkındadır ve doğayla uyumlu, ekolojik ayak izinin minimumda tutulduğu, birçok ulustan insanın barış içinde bir arada yaşayabileceği bir yerleşim yeri tasarlamayı ve hayata geçirmeyi hedeflemişlerdir. Sri Aurobindo'nun ölümünden sonra Mira Alfassa bu işe daha fazla odaklanmıştır (Guigan 2019).

Auroville'in inşa edileceği alan, 1965'te Mira Alfassa'nın arkadaşı olan mimar Roger Anger tarafından, yerleşimin ileride büyümesine olanak tanıması açısından biraz daha kuzey doğuya doğru taşınması tavsiye edilmiştir. Mira Alfassa, bu yeni alanda devasa bir banyan ağacı (Ficus bengalensis) olduğunu görmüştür. Bu ağaç Hindistan'da kutsal sayılmaktadır ve Mira Alfassa, bunun bir işaret olduğunu düşünerek projenin buraya taşınmasını onaylamıştır (Şekil 3).
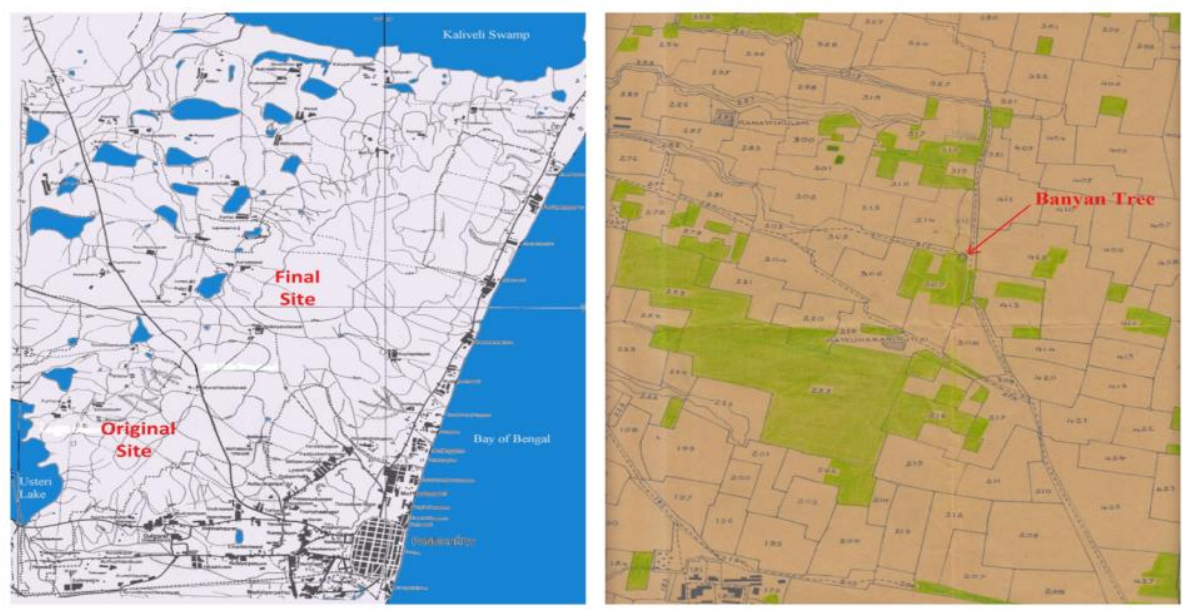

Şekil 3. Auroville ekoköyünün değiştirilen konumu ve banyan ağacı (Guigan 2019).

Auroville'in konsepti insanların birliğine adanmış, ideal bir kasaba denemesi olarak belirlenmiştir. 1930ların başlarında Mira Alfassa bu fikri geliştirmeye başlamıştır. 1960larda netleşmeye başlayan proje Hindistan hükümetine sunulmuş, akabinde de UNESCO’nun dikkatini çekmiştir. UNESCO 1966 yılında, Auroville henüz proje aşamasında iken, bu girişimin insanlığın geleceği için son derece önemli olduğunu ifade ederek hayata geçirilme sürecinde ve devamındaki her aşamasında desteğini sunacağını ifade etmiştir (Auroville Ekoköyü Resmi İnternet Sitesi 2019). Auroville ekoköyü, 28 Şubat 1968 tarihinde, 124 farklı ulustan temsilciler eşliğinde yaklaşık 5.000 kişinin katıldığı açılış töreniyle hayatına başlamıştır (Auroville Ekoköyü Resmi İnternet Sitesi 2019). Auroville'in inşa edildiği bölgede yapılan arkeolojik araştırmalar sonucunda, bazıları 2000 yıl öncesine dayanan birkaç antik yerleşimin kalıntılarına rastlanmıştır. Bölgeden çıkarılan buluntular Bharat Nivas’taki Arkeoloji Müzesi’nde sergilenmektedir (Mudgal 2008).

\subsection{Auroville Ekoköyünün Tasarımı}

Auroville'in en dikkat çekici konseptlerinden biri, Samanyolu gibi spiral bir galaksi şeklinde oluşturulan ana planıdır (Şekil 4). Merkezde Auroville'in ruhu olarak bilinen Matrimandir tapınağı bulunmaktadır. Tapınağın 
çevresinde erdem bahçeleri, toplanma alanları, amfi tiyatro gibi kullanımlar bulunmaktadır ve bu bölgeye barış alanı denmektedir; bireylerin sessizlikte konsantre olup meditasyon yapabileceği bir alandır. Amfi tiyatronun merkezinde, insanların birliğini temsil eden, kap şeklinde bir yapı bulunmaktadır. Urn of Human Unity (İnsan Birliğinin Kabı) olarak anılan bu yapıda, 121 farklı ulusun ve 23 Hindistan eyalet temsilcisinin getirdiği topraklar birleştirilmiştir. Bu merkezin kuzeyinde endüstriyel alan bulunmaktadır. 109 hektarlık bu alan, Auroville'in kendi kendine yetebilmesi üzerine odaklanmıştır. Küçük ve orta büyüklükte işletmeler, eğitim merkezleri, sanat ve zanaat atölyeleri ve yönetim birimi burada bulunmaktadır. Merkezin kuzey doğusundaki kültürel alan 93 hektar büyüklüğündedir. Eğitim, artistik ve sportif uğraşlar amacıyla kullanılmaktadır. Güney ve güney batıda konut alanı bulunmaktadır. 189 hektar olan bu alan kuzeyinde, güneyinde ve batısında parklarla sınırlandırılmıştır. Alanın \%55’i açık ve yeşil alan olarak değerlendirilirken, \%45’i ise yapısal öğeler barındırmaktadır. Merkezin batısında da uluslararası alan bulunmaktadır. 74 hektarlık bu alanda, kıtalara göre gruplandırılmış şekilde ulusal ve kültürel pavyonlar bulunmaktadır. Bu alanın ana amacı, birlikte, tüm çeşitliliği kucaklayarak yaşamanın ulusalcı yaklaşımlardan çok daha verimli ve sürdürülebilir olduğunu göstermektir. Yerleşkenin kontrolsüz büyümesini sınırlandırmak amacıyla yeşil kemer uygulaması tercih edilmiştir. Yerleşkeyi çevreleyen bu yeşil kemerde orman, çiftlikler, tarım alanları ve botanik bahçesi bulunmaktadır. 1,25 km genişliğindeki bu bölge yaklaşık 405 hektarlık alanı kapsamaktadır. İleride atık yönetimi, toprak ve su korumas1, yeraltı suyunun desteklenmesi ve çevresel restorasyon amacıyla 800 hektara kadar genişletilmesi gerektiği öngörülmektedir (Auroville Resmi İnternet Sitesi 2019).

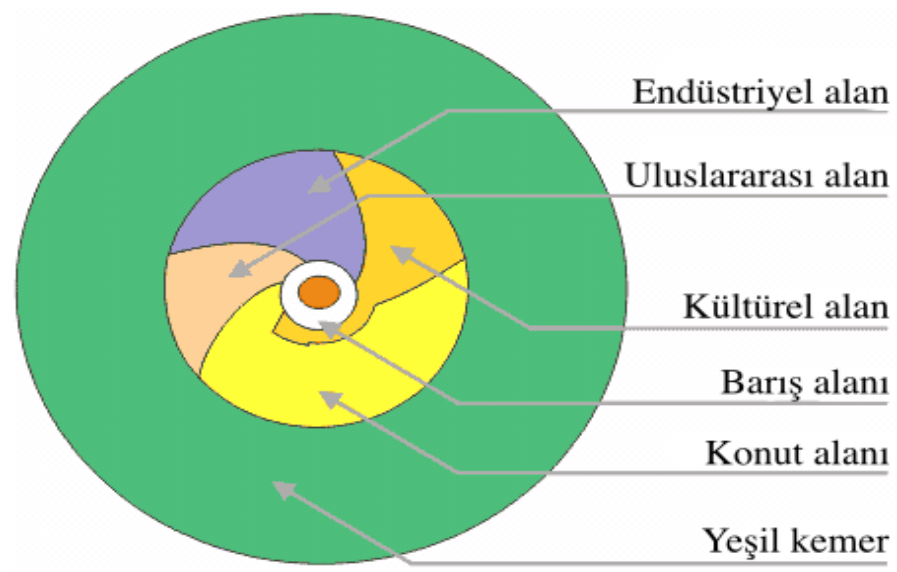

Şekil 4. Auroville’in yerleşim planı (Auroville Resmi İnternet Sitesi 2019).

Auroville'in resmi internet sitesinde paylaşılan, 2025 hedeflerini içeren master plana göre, Auroville ekoköyünün arazi büyüklükleri Çizelge 1'deki gibidir.

Tablo 1. Auroville ekoköyünde arazi kullanımı (Auroville Resmi İnternet Sitesi 2019).

\begin{tabular}{|c|c|c|c|}
\hline \multicolumn{2}{|r|}{ Arazi kullanımı } & Büyüklük (ha) & Yüzde (\%) \\
\hline \multirow{9}{*}{ 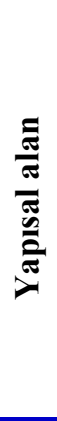 } & Konut & & 40,9 \\
\hline & a) Köy yerleşimleri & 20 & \\
\hline & b) Auroville toplulukları & 75 & \\
\hline & Ticari & 19 & 8,2 \\
\hline & İmalat \& ekonomik aktiviteler & 10 & 4,3 \\
\hline & $\begin{array}{l}\text { Kamusal \& yarı kamusal alanlar (barış alanı, bahçeler ve } \\
\text { yönetim alanları) }\end{array}$ & 65 & 28 \\
\hline & Yollar & 30 & 13 \\
\hline & Rekreasyonel kullanımlar & 13 & 5,6 \\
\hline & Ara toplam & 232 & 100 \\
\hline \multirow{8}{*}{ 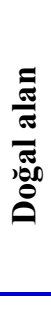 } & Yenilenmiş arazi & 598 & 34,5 \\
\hline & Zirai kullanım & & 57,2 \\
\hline & a) Zirai \& ilgili araştırmalar & 50 & \\
\hline & b) Tarım & 940 & \\
\hline & Islak alan & 45 & 2,6 \\
\hline & Kanyon, atık alanı ve diğer alanlar & 98 & 5,7 \\
\hline & Ara toplam & 1731 & 100 \\
\hline & Toplam & 1963 & \\
\hline
\end{tabular}


Auroville'i çevreleyen yeşil kemerin güney yarısında, yaklaşık 50 dönümlük bir arazide, içinde çevre eğitimi merkezi bulunan bir botanik bahçesi tesis edilmiştir. 25 dönümlük arboretum kısmında 250'den fazla ağaç türünün dikimi tamamlanmıştır. 10 dönümlük özel koruma ormanına ise 5.500 tür bitkinin dikimi tamamlanmıştır. Bölgenin yerel florasının yeniden üretimini teşvik etmek için yılda 50.000 fide üretebilen Tropical Dry Evergreen Forest (Tropikal Kurakçıl Herdem Yeşil Orman) adında bir fidanlık kurulmuştur (Auroville Resmi İnternet Sitesi 2019).

\subsection{Matrimandir Tapınağı, Erdem Odaları ve Bahçeleri}

Auroville'in tam merkezinde, yerleşimin ruhu olarak nitelenen Matrimandir tapınağının inşaatı 1992 yılında tamamlanmıştır. Gelecekte 50.000 kişinin yaşadığı bir kente dönüşmeyi hedefleyen yerleşimin tam ortasında barış alanı adıverilen geniş bir açık ve yeşil alan yer almaktadır. Matrimandir tapınağı, dünya üzerinde yeni bir bilincin doğuşunu simgeleyen, altın rengi, büyük bir lotus (nilüfer) çiçeği olarak betimlenmektedir. Ana tasarımını Mira Alfassa'nın yaptığı tapınakta, herkesin buluşup ibadet edebildiği, kürenin tam merkezinde yer alan bir iç oda bulunmaktadır. Bu iç odayı çevreleyen 12 tane de meditasyon odası yapılmıştır. Bu meditasyon odaları ise, tapınağın etrafındaki 12 adet bahçeye bağlanmaktadır. Tapınak ve çevresinin tasarımı, insanoğlunun sahip olması gereken 12 erdem baz alınarak netleştirilmiştir (Şekil 5). Şekil 6'da Matrimandir tapınağının kesiti, yapılış aşamaları, spiral galaksi modelinden esinlenilen tasarımın merkezindeki konumu, iç oda, amfi tiyatrodan görünüşü görülmektedir (Guigan 2019).

Matrimandir tapınağındaki meditasyon odaları, Mira Alfassa'nın önerileri ile netleştirilmiştir. Meditasyon odaları Feng-Shui mantığına uygun, olabildiğinde minimalist bir yaklaşımla tasarlanmıştır. Hiçbir penceresi olmayan odalar beyaz renge boyanmıştır. Ancak temsil ettikleri erdemin doğu felsefesindeki aura rengi doğrultusunda 1şıklandırılmıştır. Örneğin, Kavrayış odasında çok baskın bir şekilde turuncu renkli aydınlatmalar kullanılmış, başka renge yer verilmemiştir. Sadece iç oda olarak anılan merkezdeki ortak meditasyon / ibadet odası beyaz renktedir ve merkezinde büyük bir cam küre bulunmaktadır (Şekil 6 ve 7).

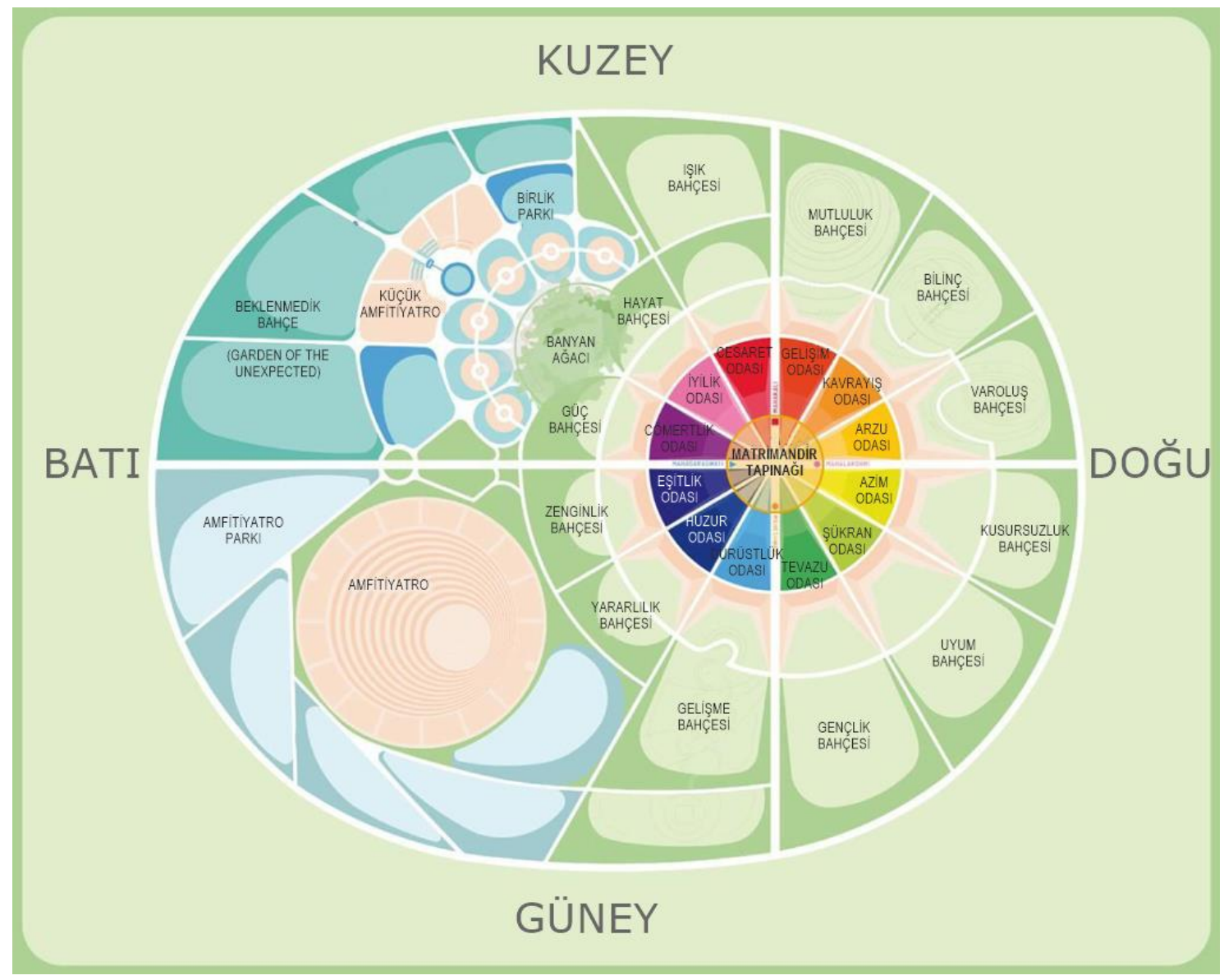

Şekil 5. Matrimandr tapınağı, erdem odaları ve bahçeleri (Guigan 2019). 

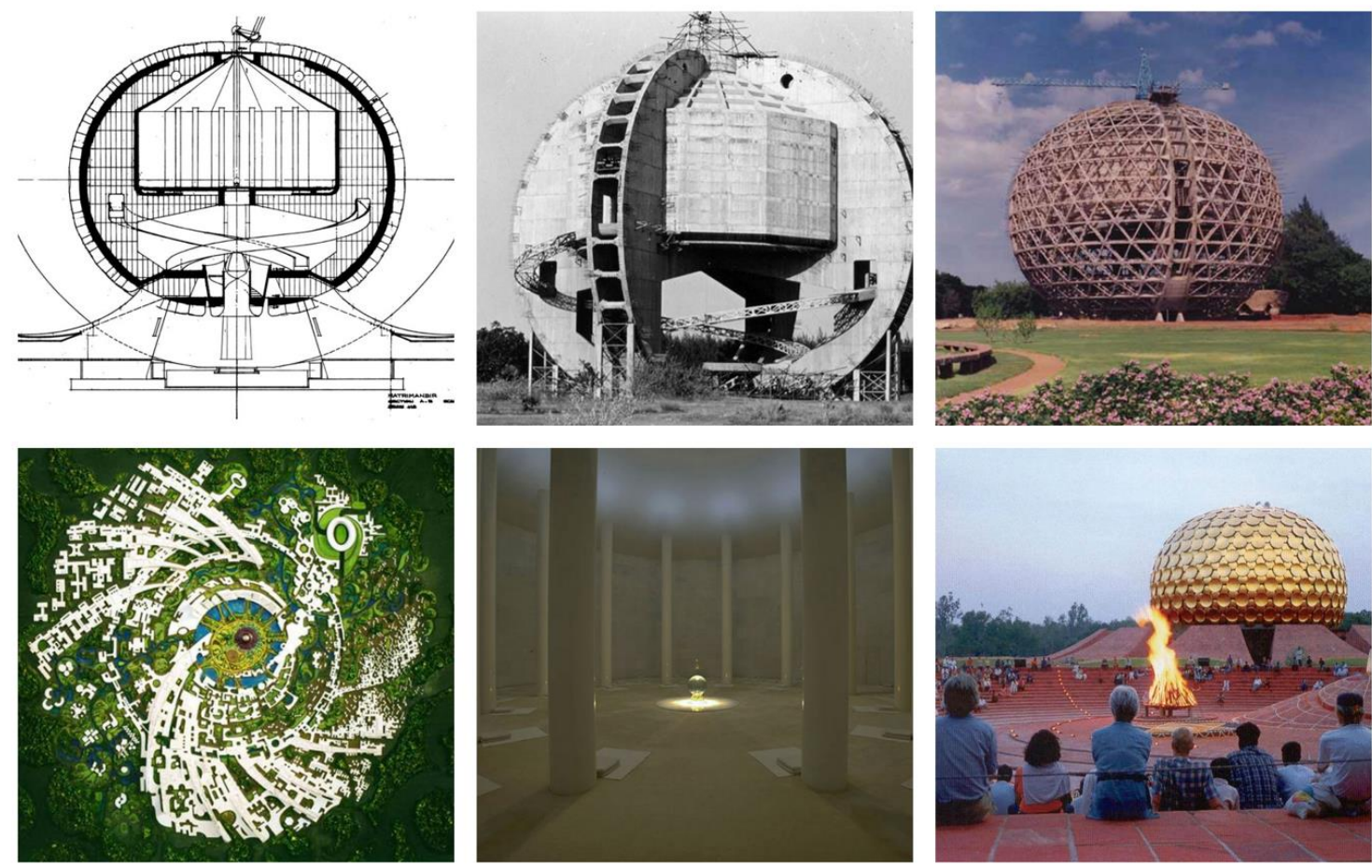

Şekil 6. Matrimandir tapınağı kesiti, inşaatı ve konumu (Guigan 2019).
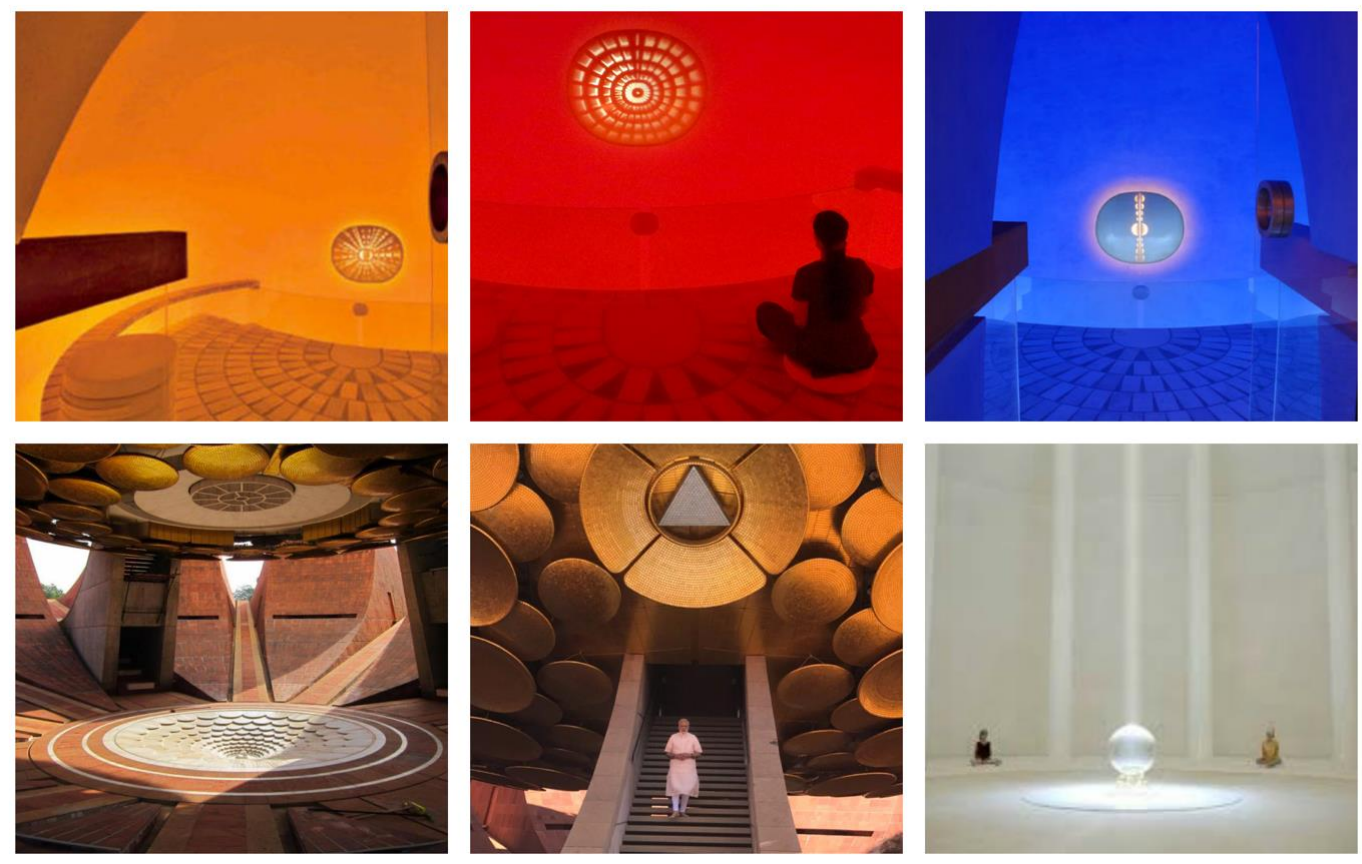

Şekil 7. Matrimandir tapınağındaki erdem odaları, girişleri ve merkezdeki iç oda (Guigan 2019).

Matrimandir tapınağını nilüfer çiçeğinin taç yaprakları gibi çevreleyen 12 bahçe bulunmaktadır. 1969'da The Mother Mira Alfassa, bahçelerin tapınakla bütünleşen özelliklerine dikkat çekmiştir. Bahçelerin her bir erdem için özel olarak tasarlanması gerektiğini, buraya gelen insanların fiziksel ve zihinsel olarak şifalanmış şekilde ayrılmasını istediğini belirtmiştir. Her bahçenin ayrı bir zihinsel terapi amacı bulunmaktadır. Bahçeler, Matrimandir tapınağı içindeki meditasyon odalarıyla ilişkili bir şekilde tasarlanmıştır. Her bir bahçede, o erdemi temsil eden özel, çiçekli bir bitki kullanılmıştır. Meditasyon odaları ve erdem bahçeleri ile ilgili bilgiler Çizelge 2'de verilmiştir. 
Tablo 2. Auroville ekoköyündeki meditasyon odaları ve erdem bahçeleri ile ilgili genel bilgiler (Guigan 2019).

\begin{tabular}{|c|c|c|c|c|c|}
\hline & $\begin{array}{c}\text { Meditasyon } \\
\text { odasının adı }\end{array}$ & $\begin{array}{c}\text { Meditasyon } \\
\text { odasının rengi }\end{array}$ & $\begin{array}{c}\text { Birleştiği erdem } \\
\text { bahçesinin adı }\end{array}$ & Bahçenin simgesel çiçeği & $\begin{array}{c}\text { Bahçede kullanılan } \\
\text { çiçeğin rengi }\end{array}$ \\
\hline 1 & $\begin{array}{l}\text { Aspiration } \\
\text { (Arzu) }\end{array}$ & Açık turuncu & $\begin{array}{l}\text { Existence } \\
\text { (Varoluş) }\end{array}$ & Hibiscus rosa-sinensis & Pembe \\
\hline 2 & $\begin{array}{l}\text { Receptivity } \\
\text { (Kavrayış) }\end{array}$ & Turuncu & $\begin{array}{l}\text { Consciousness } \\
\text { (Bilinç) }\end{array}$ & Hibiscus rosa-sinensis & Altın sarıs1 \\
\hline 3 & $\begin{array}{l}\text { Progress } \\
\text { (Gelişim) }\end{array}$ & Nar çiçeği & Bliss (Mutluluk) & Hibiscus rosa-sinensis & Soluk sarı \\
\hline 4 & $\begin{array}{l}\text { Courage } \\
\text { (Cesaret) }\end{array}$ & Kırmızı & Light (Işık) & Hibiscus rosa-sinensis & Beyaz \\
\hline 5 & $\begin{array}{l}\text { Goodness } \\
\text { (İyilik) }\end{array}$ & Eflatun & Life (Hayat) & Hibiscus rosa-sinensis & Açık kırmızı \\
\hline 6 & $\begin{array}{l}\text { Generosity } \\
\text { (Cömertlik) }\end{array}$ & Mor & Power (Güç) & Hibiscus rosa-sinensis & Koyu pembe \\
\hline 7 & $\begin{array}{l}\text { Equality } \\
\text { (Eşitlik) }\end{array}$ & Lacivert & $\begin{array}{l}\text { Wealth } \\
\text { (Zenginlik) }\end{array}$ & Nymphea sp. & Karışık \\
\hline 8 & Peace (Huzur) & Mavi & $\begin{array}{l}\text { Utility } \\
\text { (Yararl1l1k) }\end{array}$ & Hibiscus rosa-sinensis & Pembe \\
\hline 9 & $\begin{array}{l}\text { Sincerity } \\
\text { (Dürüstlük) }\end{array}$ & Açık mavi & $\begin{array}{l}\text { Progress } \\
\text { (Gelişme) }\end{array}$ & Hibiscus rosa-sinensis & Krem rengi \\
\hline 10 & $\begin{array}{l}\text { Humility } \\
\text { (Tevazu) }\end{array}$ & Yeşil & Youth (Gençlik) & Hibiscus rosa-sinensis & Turuncu \\
\hline 11 & $\begin{array}{l}\text { Gratitude } \\
\text { (Şükran) }\end{array}$ & Fıstık yeşili & $\begin{array}{l}\text { Harmony } \\
\text { (Uyum) }\end{array}$ & Hibiscus rosa-sinensis & Açık altın sarısı \\
\hline 12 & $\begin{array}{l}\text { Perseverance } \\
\text { (Azim) }\end{array}$ & Sar1 & $\begin{array}{l}\text { Perfection } \\
\text { (Mükemmellik) }\end{array}$ & Plumeria sp. & Beyaz, sarı \\
\hline
\end{tabular}

Bahçe isimleri özellikle bu şekilde sıralanmıştır. Sanskritçe'de ilk üç bahçenin adı Sat - Chit - Ananda'dır; ilahi öz anlamına gelmektedir. İlahi öze odaklanarak başlayan iyileşme ve gelişme süreci, evrimin nihai hedefi olan mükemmellik ile sonlanmaktadır.

The Mother, 1971 - 1972 yıllarında bahçe tasarımlarını daha özgün hale getirmek amacıyla her biri için özel bir çiçek seçmiştir. Doğu felsefesinde Hibiscus rosa-sinensis gücü simgelediği için iki bahçe hariç, diğerlerinde bu türün farklı renklerini tercih etmiştir. Wealth (Bolluk) bahçesinde nilüfer çiçeğinin yaşayabileceği bir havuz oluşturulmuştur. $\mathrm{Bu}$ bahçeye aynı zamanda kaktüslerin bulunduğu bir kaya bahçesi de eklenmiştir. Mükemmellik bahçesinde ise Plumeria sp. türleri kullanılmıştır (Şekil 8).

The Mother bu bahçelerin Matrimandir tapınağının bir uzantısı olduğuna şu sözleriyle dikkat çekmiştir: “... Tapınakta meditasyonunu tamamlayıp yaşam alanına dönen insanlar, doğanın müthiş güzelliği ile karşılanmalılar. İnsanlar bir bahçeden diğerine geçerken aynı zamanda bilincinin değiştiğini de hissedebilmeli. $\mathrm{Bu}$ bahçeler gerçekliğe çekmeye çalıştığımız ruhani boyutun adeta bir dişavurumu gibi olmalı. İlahi olanla kurulan öznel bağları hissettirmeli."

Matrimandir tapınağını çevreleyen erdem bahçeleri ve kullanılan bitkilere dair birkaç fotoğraf Şekil 9'da paylaşılmıştır. Şekil 10’da da Matrimandir tapınağı ve çevresindeki 12 erdem bahçesinin maketi paylaşılmıştır.

Matrimandir'i çevreleyen erdem bahçeleri ile peyzaj tasarımı tamamlanmamış, barış alanı çok farklı konseptlerde bahçe tasarımlarıyla değerlendirilmiştir. Zaman içinde, matrimandir ve erdem bahçelerinin etrafında kalan boș alanlara, insanların yaşam döngülerinden ilham alınan Garden of Birth (Doğum bahçesi), Garden of Eternal Childhood (Sonsuz çocukluk bahçesi), Garden of Youthfullness (Gençlik bahçesi), Garden of Adolescence (Ergenlik bahçesi), Garden of Age (Yaşlılık bahçesi) bahçeleri eklenmiştir. Bunların yanı sıra kelebek bahçesi ve birkaç kaya bahçesi daha amfitiyatronun çevresine yerleștirilmiştir. Barıș alanı ile ilgili tutulan kayıtların 2019 şubat ayına ait olan nüshasında bu bahçelerden bahsedildiği görülmüştür. Bahçelerin tasarımı ve kesit çizimlerine dair veriler ilgili dokümanda paylaşılmıştır. 


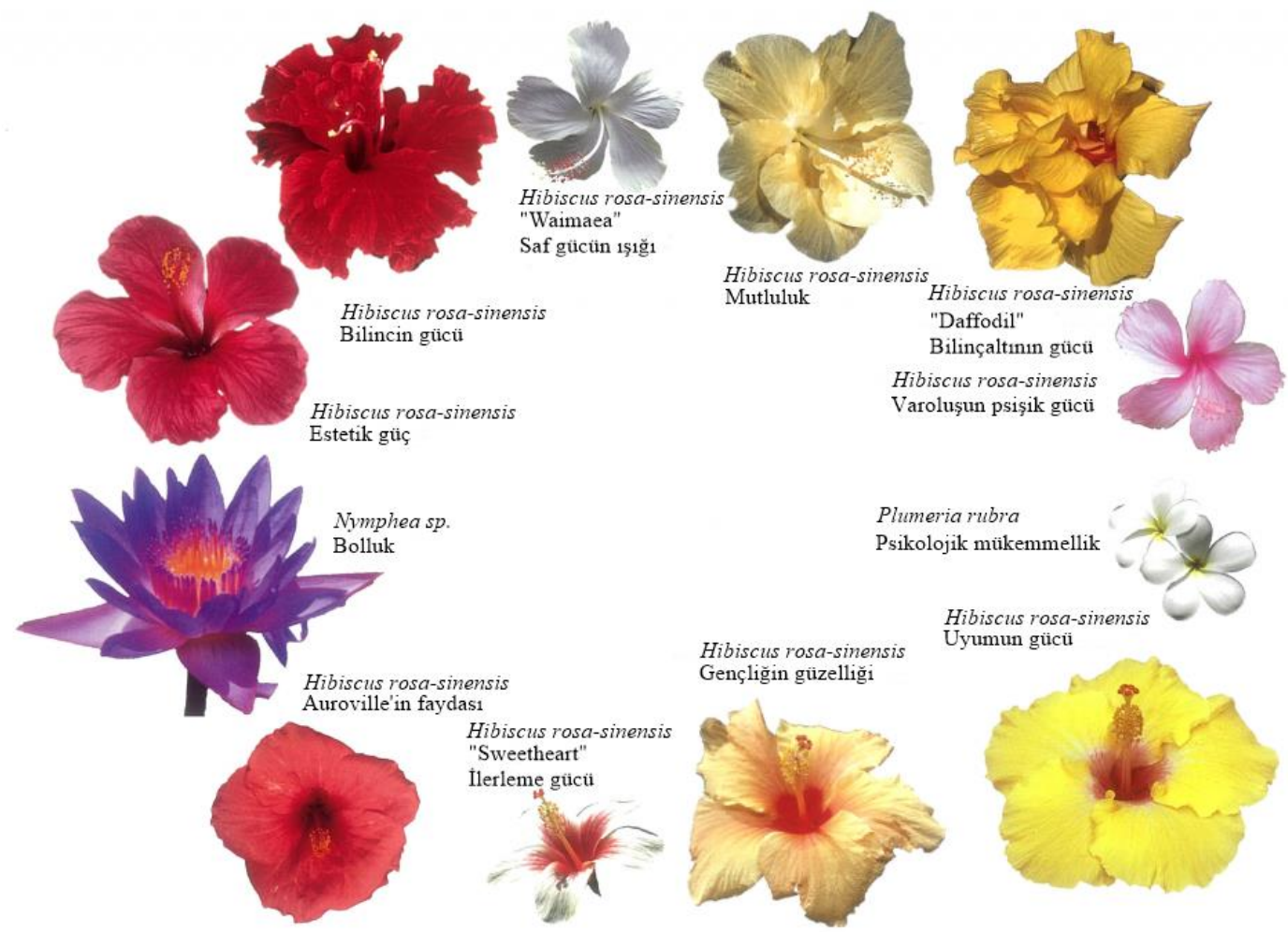

Şekil 8. Erdem bahçelerinin her biri için özel olarak seçilen çiçekli bitkiler (Guigan 2019).
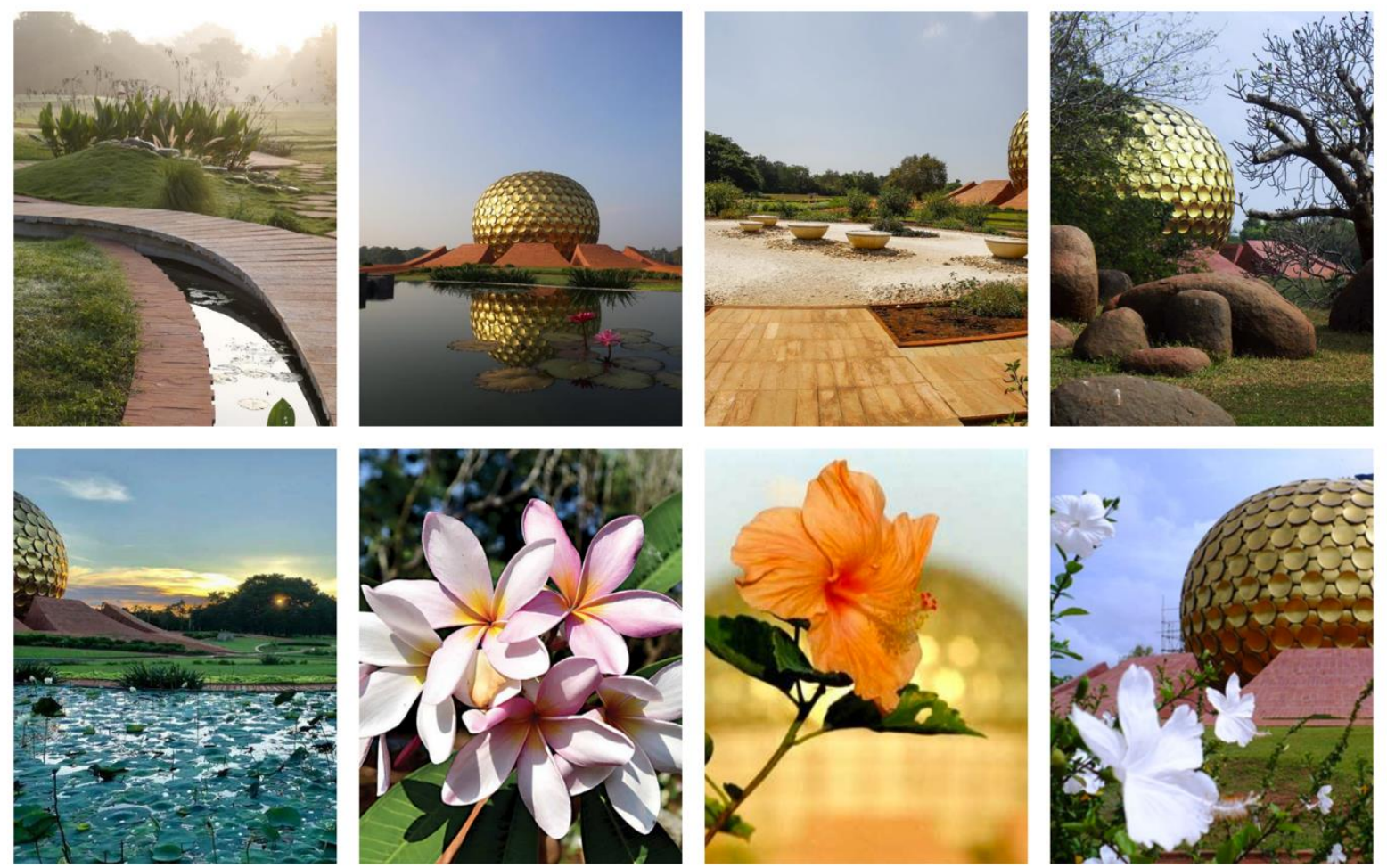

Şekil 9. Erdem bahçeleri ve kullanılan bitki türlerine dair birkaç fotoğraf (Auroville Resmi İnternet Sitesi 2019). 


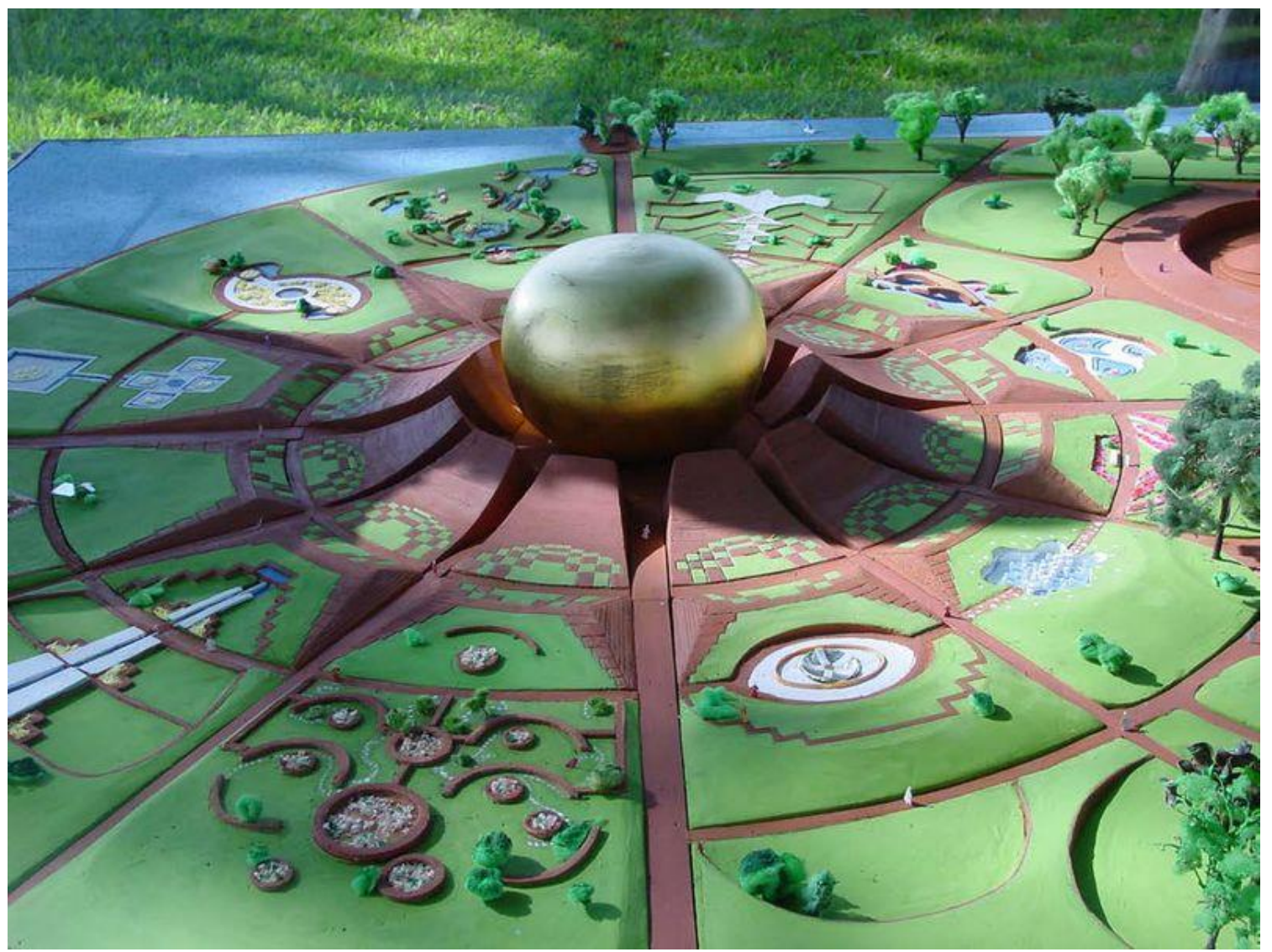

Şekil 10. Matrimandir tapınağı ve çevresindeki erdem bahçelerinin maketi (Matrimandir Resmi İnternet Sitesi 2020).

\section{Sonuç}

Auroville ekoköyü örneğinde de görüldüğü üzere, ekoköylerin en güçlü boyutu spiritüel boyutudur. Bu boyutun güçlü kalabilmesi halinde sosyal, ekonomik ve ekolojik açıdan sürdürülebilirlik daha sağlıklı bir şekilde sağlanabilmektedir. Bir birey bir ekoköyde yaşamaya başlayıp bir süre sonra bu yaşam tarzından vazgeçip kente dönerse, yeterli spiritüel itici güçlere sahip olmadığı iddia edilebilir. Tüm bir komün bu şekilde davranırsa ekoköy kapatılır ve girişim başarısız olmuş olur. Dolayısıyla ekoköylerde spiritüel boyutu canlı tutmak, onu güçlendirmek için kişilere bireysel ya da grup aktivitelerine katılım imkânı sağlamak son derece önemlidir. Buddha felsefesinde yer aldığı üzere, kişi kendi ruhani dengesini kuramadıkça dünyaya bir denge getiremez.

Auroville'in kurucusu olarak görülen Mira Alfassa'nın (The Mother), Matrimandir tapınağı bittiğinde şu sözleri arşive geçmiştir:

- Auroville kimseye ait değildir. Auroville bir bütün olarak insanlığa aittir. Ancak Auroville'de yaşamak için ilahi bilincin istekli bir hizmetçisi olmak gerekir.

- Auroville bitmeyen bir eğitimin, sürekli ilerlemenin ve asla yaşlanmayan, genç bir enerjinin yeridir.

- Auroville geçmiş ve gelecek arasında kurulabilecek sağlıklı bir köprü olmak istemektedir. İçeriden ve dışarıdan, tüm keşiflerden yararlanan Auroville, cesurca gelecekteki hakikatine doğru ilerleyecektir.

- Auroville gerçek bir insan birliğinin canlı bir düzenlemesi için maddi ve manevi araştırmaların yürütüldüğü bir yer olacaktır.

$\mathrm{Bu}$ açıklamadan da anlaşıldığı üzere, Auroville spiritüel boyutu son derece güçlü olan bir ekoköydür. Bu bağlamda, köyde yaşayan insanların erdemlerini geliştirmiş, zayıflıklarını yok etmiş olmaları beklenmektedir. Mükemmel insan profiline ulaşabilmek için de incelenen bu meditasyon odaları ve erdem bahçeleri tasarlanmıştır.

Bir peyzaj tasarımının, çok da büyük olmayan bir bahçenin, insanların sahip olması gereken erdemlerden birini niteleyecek yoğunlukta tasarlanması, bahçede yapılan meditasyonlarla bu ruhani eksiklerin giderilmesinin 
hedeflenmesi, Auroville ekoköyünün hem spiritüel gücünü hem de terapi bahçelerinin uzak doğu felsefesinde ne kadar ciddiye alındığını göstermektedir. Terapi bahçelerine bu kadar önem veren ve hakkında her ay, yıllar boyunca rapor tutulan başka bir ekoköy bulunmamaktadır.

Peyzajın, insan ve doğa, hatta insan ve kozmik enerji arasındaki ilişkiyi spiritüel açıdan dinç tutabildiği ve geliştirdiği Auroville ekoköyü erdem bahçeleri örneğinde görülmektedir. İnsanlar, onları çevreleyen mekân aracılığı ile belirli bir düşünceye, duyguya veya enerjiye yönlendirilebilir. Japon bahçelerinden bu yana insanların iç enerjisine hitap eden, doğayla kurulan ilişkiyi güçlendiren bir peyzaj tasarım akımı görülmemiştir. Daha çok yapılarla bütünleşen, onların enerjisini, otoritesini dış mekâna yansıtan ve orada devamını sağlayan tasarımlar ortaya çıkmıştır. Peyzajın psikolojik ve terapik yönleri daha çok tartışılmalı, insan davranışları ve duygu durum değişikliği üzerindeki etkileri ile ilgili daha fazla araştırma yapılmalıdır. Bu alanda akla gelen ilk isimlerden olan, Michigan Üniversitesi Psikoloji Bölümü öğretim üyeleri Rachel Kaplan ve Stephen Kaplan'ın, peyzajı psikolojik bileşenlerini irdeledikleri, oldukça başarılı pek çok araştırması bulunmaktadır. Peyzaj mimarları da, tasarımın sosyal ve psikolojik etkileri üzerine daha çok eğilmeli, renkler ve formların somut \& soyut, birincil \& ardıl etkilerini iyi kullanabilmelidir. Peyzajı nicel yöntemlerle değerlendirme eğiliminin yanında, kullanıcıların duygu durum değişikliklerini iyi yöneten nitel yönleri üzerine yapılan çalışmalar arttırılmalıdır.

Diğer yandan, dünyanın bozulan sağlığını düzeltme amacı güden ekoköy girişimleri, aslında duyarlı insanların bir çeşit dünyadan özür dileme yöntemi olarak değerlendirilebilir. Ekoköylerde yaşayan bireyler, insanoğlunun dünya ekosistemine verdiği zararın farkında ve kendisi üzerinden bu zararı en aza indirgeme gayreti içindedir. Dünyadaki yaşamın devamlılığı için özellikle kentler kontrol altına alınmalı, ekoköy, ortak konut projeleri, ekokent gibi sürdürülebilir yaşam formları ve benzeri girişimler desteklenmelidir.

\section{Teşekkür}

Doktora tezim kapsamında da araştırdığım ekoköyler hakkında fikrine sık sık danıştığım, Auroville ekoköyünün tarihi ve tasarım prensiplerine dair çok değerli bilgileri benimle paylaşmaktan çekinmeyen, sabırla her bir soruma paragraflarca cevap yazan Auroville Ekoköyü Arşiv Sorumlusu Gilles Guigan’a sonsuz teşekkürlerimle.

\section{Kaynaklar}

1. AHTA (2012). Definitions \& Positions. The American Horticultural Therapy Association. Web Sitesi: https:/www.ahta.org/assets/docs/definitions\%20and\%20positions\%20final\%206.17.pdf. Erişim tarihi: 16.01.2020.

2. Auroville Resmi İnternet Sitesi (2019). Web sitesi: www.auroville.org. Erişim Tarihi: 15.01.2019 23.12.2019.

3. Gangopadhyay, $\mathbf{N}$ and Chakraborty, P. (2015). An Alternative Model of Sustainable Living: the case of Auroville in India. IOSR Journal Of Humanities And Social Science (IOSR-JHSS), Volume 20, Issue 11, Ver. V (Nov. 2015) PP 38-49

4. Google Haritalar (2019). Web Sitesi: www.maps.google.com Erişim Tarihi: 23.10.2019.

5. Guigan, G. (2019). İnternet yoluyla yazılı ve görüntülü görüşme. Gilles Guigan, Auroville ekoköyü arşiv sorumlusu, Hindistan.

6. Jonge, N. K. M. (2017). Embodiment of Sustainability in Auroville. Master thesis in Department of Cultural Anthropology, Sustainable Citizenship in Utrecht University, Netherlands.

7. Matrimandir Resmi İnternet Sitesi, (2020). Web Sitesi: https://www.matrimandir.org/. Erişim Tarihi: 14.06.2020.

8. Mudgal, V. (2008). Designing Base Station for Living Routes: Auroville, India. Master thesis in Department of Landscape Architecture and Regional Planning, University of Massachusetts, Amherst, the USA.

9. Mueller, M. (2012). Global Ecovillage Network - Living and Learning Centres. Web Sitesi: http://gen.ecovillage.org/sites/default/files/files/ll_single.pdf. Erişim Tarihi: 01.11.2018. 